\title{
Use of Children's Popular Culture in Literacy Curricula: An Analysis of the Papers by Parry (2002) and Dickie and Shuker (2014) through the Lenses of "No Research Can Be Value-Laden"
}

\author{
Fatma Aslanturk Altıntug $\breve{g}^{1} \&$ Emre Debreli $^{1}$ \\ ${ }^{1}$ Faculty of Education, European University of Lefke, Gemikonağ , Turkey \\ Correspondence: Emre Debreli, Faculty of Education, European University of Lefke, Gemikonağı, Turkey. Tel: \\ 90-392-660-2660. E-mail: edebreli@eul.edu.tr
}

Received: October 16, 2017

Accepted: October 24, 2017 Online Published: October 30, 2017

doi:10.5539/jel.v7n1p174

URL: https://doi.org/10.5539/jel.v7n1p174

\begin{abstract}
This paper focuses on the importance of children's out-of-school experiences as their popular culture and discusses how such experiences contribute to their creativity and critical thinking. In addition to this, the paper also discusses the critical role of researchers' values in terms of how values affect the design and process of research. From this standpoint, it analyses two research articles, namely as: "Popular culture, participation and progression in the literacy classroom", by Parry (2014), and "Ben 10, superheroes and princesses: primary teachers' views of popular culture and school literacy", by Dickie and Shuker (2014). Throughout the analysis, the paper discusses how the values of the authors' of these papers affected their selection of the research topics, as well as the process of research, by bringing out the importance of critical literacy in pre-school curricula.
\end{abstract}

Keywords: literacy, critical thinking, creativity, values, research, popular culture

\section{Introduction}

We need to become the sorts of subjects who actively desire to reinvent subjectivity as a set of mutant values and to draw our pleasure from that, not from the perpetuation of familiar regimes (Braidotti, 2013, p. 93).

As being educators for a considerable amount of time, we have always valued learning through reflection and reflective skills which are likely to promote learning, and more significantly enhance learners' creativity and critical thinking. We firmly believe that students should be given opportunities to learn how to question, criticize, encounter problems and find solutions. In other words, they should be provided with appropriate beneficial activities and tasks which would empower them to reflect on their learning and enhance their creativity and critical thinking in their academic life. From this standpoint, encouraging learning through reflection and teaching how to think creatively and divergently should start as what Saccardi (2014) suggests - even in preschool classrooms. Educators, therefore, should first start fostering reflective skills in the young and get them to adopt a habit of thinking creatively and expressing themselves freely and autonomously. In order to do this, the first task is to gain valuable information about our students. In other words, we should discover who learners really are and know what their interests and values are. As Pahl and Rowsell (2011) noted an understanding of children's real identities can be achieved by recognizing their out-of-school interests and artefacts, as well as their values. It is our belief that this recognition would be helpful in developing teaching strategies in which students will be more motivated and enthusiastic to reflect on their learning. Children's values and interests can be uncovered through observations. Watching children during play and whilst interacting with each other helps teachers to comprehend their learners and have an awareness of what their identities, values and interests are. Teachers' role in this regard is well exemplified by Machado as:

Teachers must be part detective and part researcher, shifting through the clues children leave, collecting data, testing hypotheses, and examining the way children really are to make a credible record of their growth and development (Machado, 2014, p. 168).

Observing students helps us visualize their real, home identities. As Pahl (2012) contends every object that a child uses matters and tells us a story concerning the child's identity and also enables us to perceive what they really value. Understanding who they really are and what they really value is very important in order to enhance 
students' reflective skills. As Scanlan (2010) states, students are more enthusiastic to take part in activities in which they are shown something from their life experiences and "shared worlds" (p. 33). They become more willing to participate and this willingness causes them to be more creative and productive. Moreover, "creativity requires prior knowledge" (Webb \& Rule, 2012, p. 380) and this prior knowledge emerge when children are given an opportunity to use their out-of-school experiences in the classroom. Therefore, if we want the learners to reflect on their learning, think creatively and critically, we should gain an understanding of students' real identities are, and draw on their out-of-school experiences and interests in their learning experiences. In other words, children can be more responsive and creative if their "voices" are appreciated and used in the classroom (Johns et al., 2012).

In today's world, most of the children are attracted to the superheroes, Disney characters, and related artefacts through the engagement with media and popular culture (Marsh, 2000; Wohlwend, 2011). They all love talking about their favourite cartoon characters, dressing and behaving like them. In their plays they pretend to be one of their heroes or idols. Even the shyest child becomes very active when engaging with popular culture because this engagement "allows children to share aspects of their cultural identity, to explore shared worlds such as those related to popular culture" (Scanlan, 2010, p. 35). Wohlwend and Peppler (2015) contend that children become more willing to participate and take part in activities which they come across during their out-of-school lives, such as games, favourite characters, media texts and other artefacts. Therefore, this engagement with their popular culture is extremely motivating and this motivation drives them to be more participative and creative in their classes. In this respect, as Teichert (2015) stated in her book review, listening to children's voices and valuing their out-of school interests can motivate them in the learning process and extends their critical thinking.

On the other side, conducting a research enables us to investigate and scrutinize certain subjects in which we are both curious and interested in. We, as educators, work in a variety of institutions and disciplines and have an opportunity to perceive the nature of the learning process and evaluate the learning outcomes from different perspectives, as we all have divergent interests, concerns and values. These differences among our values often cause us to identify issues and implement them in a research, directly or indirectly. Our assumption here is that we cannot deny the influence of our values when we approach a specific research. For this reason, we chose two articles and scrutinized them in this paper. Both articles chosen, "Popular culture, participation and progression in the literacy classroom" and "Ben 10, superheroes and princesses: primary teachers' views of popular culture and school literacy", discuss the importance of children's out-of-school knowledge of popular culture to be incorporated into the school curriculum, and to provide opportunities to incorporate the children's voices and values also into the school curriculum. Moreover, the articles demonstrate a demand for a change in school curriculum, in which, we believe, children will have the freedom to use their own voices, contribute to their own learning and more importantly will be provided with opportunities to engage themselves in creative and critical thinking. Our first aim here is to show how our own values affected our choice of these two specific research papers among the hundreds of others, and more importantly, how the authors of these articles were affected by their values in their selection of the methodologies throughout their research.

\section{Values and the Choice of Research Method}

It is a common sense that we all have different interests, viewpoints and values. The differences in our interests and values cause us to choose different routes in educational research. Therefore, it can be said that in these different routes we conduct reflexive practice because when "our scientific practice is reflexive ... values are fully engaged as objects of inquiry in their own right and that methodological choices are informed by those value commitments and recursively explored in the research process" (Longhofer \& Floersch, 2014, p. 529). We believe that this paper highlights an important point enabling us to gain an understanding of how values work within a research. The articles used in this paper were not given to us as we chose to use them as they manifest our hidden values. Through reading and examining the articles, our embedded assumptions, beliefs and values are revealed and more significantly we are provided with an insight into the role of the values in the research process. While examining the articles, we had a chance to observe the implementation of different methods. In these articles, the authors aimed to discuss the importance of incorporating children's expertise of popular culture into the literacy curriculum. However, they both pursue their research by using and implementing different methods. This is because each has a different background, perspective and position and this difference shapes the conduct of their research:

The worldview and background of the researcher affects the way in which he or she constructs the world, uses language, poses questions, and chooses the lens for filtering the information gathered from 
participants and making meaning of it, and thus may shape the findings and conclusions of the study (Berger, 2015, p. 220).

The above quote is exemplary in highlighting how personal values have an effect on an individual's attitudes and perspectives because a researcher's background and position embodies personal values and these values are reflected in different attitudes. In his article, Greenbank (2003) uses Rekerach's categorisation of values in order to show the place of the values in research methods. According to Rekerach (1973), individuals' value system consists of a bunch of moral, competency, personal and social values and these values have an influence on an individual's attitudes and behaviour. The assumption here is that values are actually the hidden, embedded forces that contribute to the choice of research method and shape the implementation of the research. This is also put forth by Pring (2005) as:

...no research methodology is value-free, or free of the social and political context in which it is used. Of course, over a period of time, people in the same social and cultural context will reach general consensus over the values which shape the goals, methods and interpretations of the research (p. 231).

On this basis, we would argue that educational research is a value-laden and reflexive practice, as from the choice of the research topic to the conduct of the research, researchers give an ear to their values (Berger, 2015; Pring, 2015). In other words, what is considered to be worth examining, evaluating and questioning in the research process is sprung from researchers' values. Furthermore, there is a range of research methods used in a variety of research because variety of values contribute to variety of research methods, and owing to the individual differences among the researchers and the scholars, different research models and approaches are used when undertaking a research. In each model, researchers aim to go beyond their personal experience, thoughts, feelings and opinions and examine an idea, scrutinize an issue and try to solve a problem. In addition, a variety of models help researchers to use different paths to address different questions, which emerge from the topic that the researcher is interested in researching. By doing this, researchers reflect their values because values help identifying research interests and later these values contribute to the creation of the realities about the case (Pring, 2005).

In every research process there is a personal involvement when implementing research methods. Whether it is a qualitative or quantitative method that is utilized in the research process, they all reflect the researcher's personal values and beliefs. In order to collect data, researchers form and ask different kinds of questions. For instance, the questions that are asked in surveys or in interviews are the researchers' own personal questions and we do not believe that these questions are value-neutral. When shaping any kind of research questions, researchers draw on their experiences and background knowledge and attempt to reach the findings. Accordingly, researchers contribute to the creation of the findings:

Evaluation outcomes are not descriptions of the "way things really are" or "really work", or of some "true" state of affairs, but instead represent meaningful constructions that individual actors or groups of actors form to "make sense" of the situations in which they find themselves. The findings are not "facts" in some ultimate sense but are, instead, literally created through an interactive process that includes the evaluator... as well as the many stakeholders... What emerge from this process is one or more constructions that are the realities of the case (Pring, 2005, p. 231).

Above quotation is particularly relevant to the existence of multiple realities and subjectivity of the researcher in the research process. In this regard, the researcher is not seen merely as an observer, but as a participant and as a contributor. As an active evaluator, the researcher is not outside of what is being researched. In contrast, the researcher takes part in the implementation of the research methods and so contributes to the research findings. When the researcher is not separate from what is being researched, his/her values are unavoidably researched and what is found and the research findings are not discovered but created and constructed (Pring, 2005). This view is opposed to dualistic, objective epistemology in which the researcher "stands outside the arena of the observed" (Guba \& Lincoln, 1989, p. 12) and aims to discover the findings. In an objective epistemology, subjectivity of the researcher does not exist and the research is value-neutral. In other words, the researcher makes no attempt to interact with what is researched but aims to "find the way things really are and the way things really work" (Pring, 2005). However, even when using a positivist, objective approach, the researcher reflects his/her values on research methods without noticing it. As mentioned earlier, the questions that are asked when adopting qualitative methods are embedded with the researcher's values. "Even before data is analysed, interpreted and presented the researcher's method of sampling, experimental design or questionnaires are likely to reflect their (often unconscious) values" (Greenbank, 2003). So, there can be no separateness from what is being researched as even when preparing the interview or survey questions the researcher needs to use his/her 
own personal experiences in which the values exist. “...those who profess to carry out value-neutral research are deluding themselves. They are also misleading others by presenting their research as depersonalised and value-free" (Greenbank, 2003). Therefore, whether a research is conducted by using positivist or interpretivist models it cannot be "value-neutral" and "depersonalised" because one way or another research methodologies are influenced by the values, which indirectly shape the research findings at the end.

\section{Evaluations Methods Used in the Articles}

As noted earlier in the introduction section, the articles chosen for this assignment are likely to reveal our own values. Both papers discuss the role and importance of popular culture in the school curriculum and also aim to highlight the possibility that popular culture motivates children when integrated with school literacy activities. Whilst reading and examining the papers, we noticed that drawing on children's experiences and out-of-school practices can promote learning and enhance the students' creativity and critical thinking as opposed to rote learning. Each author pursues a different route when undertaking their research. In her paper, which was published in 2014 and named as popular culture, participation and progression in the literacy classroom, Parry scrutinizes "the necessity of including popular culture experiences in literacy teaching in order to ensure that children are able to articulate and develop key conceptual understandings". For this purpose, she drew on data from a recent media literacy research project focused on media literacy and learning progression. In this project implementation process, action research was used and this was then followed by questionnaires and interviews. On the other hand, Dickie and Shuker's article which was published in 2014, and named as Ben 10, superheroes and princesses: Primary teacher's views of popular culture and school literacy, followed a different path while conducting their research. In their paper they aim "to illustrate how teachers can avoid a narrow interpretation of literacy curriculum by drawing on children's expertise in popular culture". In their research process they collected data by utilising two stages. In the first they used a comprehensive postal survey and in the second they used a case study.

It is very clear that the authors in their respective papers pursue different routes whilst implementing the research methods. Although both papers value children's experiences with popular culture and aim to display the benefits of drawing on these experiences in literacy classes, they used different methods. This is because they hold different ontological and epistemological positions. Ontological assumptions are "the assumptions about the nature of reality and the nature of things" (Cohen et al., 2011, p. 15) and these assumptions "concern the very nature of essence of the social phenomena being investigated" (p. 5). Hitchcock and Hughes (1995) argue that ontological assumptions result in epistemological assumptions, which are "the ways of researching and enquiring into the nature of reality and the nature of things" (Cohen et al., 2011, p. 15). The authors also claim that due to the contrasting and different ontological and epistemological positions, the researchers favour different methods and approaches when conducting the research (ibid.).

What now follows is an examination of each paper in detail to conceive how the values of the authors influence the methods they implemented.

\subsection{Article I: Popular Culture, Participation and Progression in the Literacy Classroom}

Parry's article (2014) demonstrates the necessity to integrate the students' home and school experiences in the learning process in order to enable students to "articulate and develop key conceptual understandings" (p. 14). She highlights the importance of valuing students' experiences with home digital literacy, which is part of their popular culture. She claims:

The inclusion of children's home digital literacy practices can be central to the development of a productive pedagogy underpinned by a concern for social justice and equality of opportunity in education (p. 14).

She argues that the use of students' experiences with popular culture do not only enhance their motivation to learn but also contribute to the development of their conceptual understandings. In order to support her statement she utilized and examined the data attained from a research project called "Developing Media Literacy: Towards a Model of Learning Progression". This project aimed "to explore the practice of media education in schools" (p. 15) and was undertaken by using action research, which was then followed by collecting data through a questionnaire and interviews. In her paper, Parry observes and investigates various activities that "focused on media language and narrative" (p. 15). She spent a week in observing, making video recordings and collecting examples of what the children produced. In her research, she had a focus group consisting of 8 and 9 year old children, who belong to different gender, class and ethnic groups. The focus group also varied "in terms of learning dispositions and social and cultural experiences" (p. 15). Throughout the week, different activities related to scary stories were given to the students "to explore how children's spontaneous concepts about media language might become scientific" (p. 
16). All the activities were planned and then implemented carefully in order to enable the research team to comprehend "what children could articulate about narrative and uses of media language" (p. 16) and how to enhance their learning. In the activity preparation process students' preferences and values were considered in such a way that they were invited to bring in their favourite scary books, films and games. By doing this they aimed to value children's experiences with scary stories because children are more willing and motivated to take part in the activities that include something from themselves. In their data collection process the students' involvement in the activities was very important because the data we was collected through observations. Therefore, motivating and encouraging students to participate in the activities is of the utmost importance because in the method (action research) that they implemented, the main interest was on the participant. This is why before implementing the activities they tried to comprehend and then considered the students experiences with scary stories.

The interpretative paradigm, in contrast to its normative counterpart, is characterized by a concern for the individual... As we have seen, the central endeavour in the context of the interpretive paradigm is to understand the subjective world of human experience. To retain the integrity of the phenomena being investigated, efforts are made to get inside the person and to understand from within (Cohen et al., 2011, p. 15).

Looking at the above quote, there is no doubt that whilst undertaking the research they favoured the interpretive paradigm in which the researcher is a subjective observer and tries to "grasp the subjective meaning of social action" (Bryman, 2012, p. 30) and "examine the situations through the eyes of the participants rather than the researcher" (Cohen et al., 2011, p. 15). At this point we want to focus on action research and show how Parry's research is conducted by taking an interpretative stance. Kemmis and McTaggart (1988) define action research as follows:

Action research is a form of collective self-reflective enquiry undertaken by participants in social situations in order to improve the rationality and justice of the own social or educational practices, as well as their understanding of these practices and the situations in which these practices are carried out. The approach is only action research when it is collaborative, though it is important to realize that the action research of the group is achieved through the critically examined action of individual group members (Kemmis \& McTaggart, 1988, p. 5).

The focus group in the study was subjected to different activities and in the article "five selected instances" (p. 17) from these activities were used to "demonstrate the impact of specific pedagogic strategies on children's conceptual understanding of film language" (p. 17). Throughout the activities students were provided with opportunities to reflect their self on their learning. In the first instance the students were given an opportunity to draw on their experiences on scary stories in order to "frame the activity". Students worked "collaboratively" in groups and could successfully describe "visible narrative elements" which were chosen from the films and TV programmes in which they were interested in. Moreover, they were prepared for the next task, which enabled them to draw on their experiences and "share their existing repertoires of narrative" (p. 17). The task also provided "a more complex vocabulary in terms of film language to enable the children to express the full extent of their understanding in their written descriptions" (p. 18). In the next task students were shown a clip of a TV animated version of Batman and then asked to answer the questions using a set of 12 still. In this part of the activity we noticed that the researcher encouraged the student (Joe) to go further by asking "What does that mean?". As indicated earlier, a researcher adopting an interpretative stance is interested in "grasping the subjective meaning of social action" and from his/her own perspective. For this reason, "social science is seen as a subjective rather than an objective undertaking, as a means of dealing with the direct experience of people in specific contexts" (Cohen et al., 2011, p. 15). The child's response to the question enabled the researcher to understand how he interprets and perceives the matter. Therefore, by asking that specific question, the researcher gained a subjective meaning of the child he observed. In other words by taking part in the activity the researcher could easily observe how Joe was able to use his existing knowledge of films in the activity. Before implementing the activity, Joe was introduced as a student with severe learning difficulties. However, throughout the activity he was very motivated and responded to the questions promptly. This is because in the activity he was given a chance to draw on his experiences with scary stories and films. His understanding of a set of semiotic tools motivated and enabled him to participate in the group. Moreover, his understanding and knowledge of the scary texts and films also encouraged the other students in his group to use their own experiences with the scary texts and films. Therefore the activity which allowed the students to draw on their experiences with scary texts increased the motivation of the students and then empowered them to participate and "connect with, interrogate and develop their existing conceptual understandings of story and begin to make these understandings explicit" (p. 17). By valuing the children's experiences with scary stories the research team showed how much they cared about the students they observed. The questions that were asked to 
encourage the students to articulate specific answers related to their prior knowledge proved the researchers' personal involvement in the activity. We believe that this involvement contributed to the research findings because even a little subjective help or encouragement can change the flow of the research. McLaughlin and Ayubayeva (2015) claim that whilst implementing action research, the researcher is on a journey and this journey "engages values, beliefs and emotions" (p. 64). Therefore we would claim that while valuing the children's experiences with popular culture, the researchers mirrored and reflected their emotions and values. In other words, the way in which they directed and implemented the activity is influenced by their values.

By favouring the interpretive paradigm and implementing action research, the researchers in Parry's paper did not aim to produce new knowledge but wanted to "demonstrate the necessity of including popular culture experiences in literacy teaching in order to ensure that children are able to articulate and develop key conceptual understandings" (p. 14). Thus, whilst implementing the method, the researchers were engaged in the activity, not to seek for a new knowledge but to enhance the children's conceptual understandings in literacy settings. In the paper, it is indicated that the children were addressed questions and were encouraged to participate in the task. "Far from blandly valuing the children's ideas on the basis of popular culture, the teacher took an interrogatory role, which pushed the children to consider meaning and intention directly" (p. 21). In this regard, we believe that by taking "an interrogatory role" and through "critical self-reflection of their own practice" (Wood, 2014, p. 51) the researchers' values were revealed and shaped the conduct and then the outcome of the study:

Therefore, when teacher researchers are putting into practice a particular strategy or are implementing a curriculum proposal at the same time they are testing out the values as much as the efficaciousness of the strategy or proposal... Action research, in examining the implementation of a curriculum proposal, involves, therefore, a critique of the values which are intrinsic to the practice. Such a critique will reflect the values which the teacher brings to the practice, and those values will in turn be refined through critical reflection upon their implementation in practice. Action research captures this ever-shifting conception of practice through the attempt to put into practice certain procedures which one believes are educational (Pring, 2006, p. 135).

Taking the above quote into account, it can be said that the method used in Parry's paper is very value-laden and there is no doubt that the researchers' values help shape the conduct of the research. In her paper Parry values children's "popular culture" and believes that using children's experiences of popular culture can make their learning experiences more meaningful and "the inclusion of popular culture enables the children to demonstrate their understandings of narrative and media forms" (p. 14). Thus, Parry in her paper is trying to highlight the significance of drawing on children's home digital literacy experiences and then incorporating them into the school literacy curriculum. So, as Pring (2006) stated in the given quote above this is "a curricular proposal". Through laying an emphasis on the importance of using and including children's experiences of popular culture in school settings, she is actually reflecting her concern in the matter. Her interest in the matter urges her to conduct the research and make a suggestion based upon the research findings. For this reason, in her paper, she is actually suggesting a way in which children will be motivated to participate in the activities that help them develop "key conceptual understanding" (p. 14) and strengthen their literacy skills. This "curricular proposal" is influenced by the researcher's values and beliefs. Accordingly, throughout the implementation of the activity she was reflecting her own values, which in turn embodied and shaped the process of the research. In this respect we would state that Parry's paper favours and demonstrates a value-laden approach.

\subsection{Article II: Ben 10, Superheroes and Princesses: Primary Teachers' Views of Popular Culture and School Literacy}

In their paper Dickie and Shuker (2014) scrutinized the primary teachers' opinion about integrating children's expertise of popular culture into the literacy curriculum. While reading the background part of the article, we noticed that the authors capitalized on the approach named "New Literacy Studies" before undertaking their research. This approach "focuses on the social, cultural and political contexts of the users rather than on the technical skills of reading and writing" (p. 32). So by valuing the ideas demonstrated by "New Literacy Studies", Dickie and Shuker show which approach they favour in literacy teaching. In addition to this, they also focused on "the theoretical views of The New Zealand curriculum" and highlighted the role of "Effective Literacy Practice" in New Zealand primary schools. The learning approaches as outlined in "Effective Literacy Practice" are concerned with meaning and value students" "out-of-school practices" and encourage the teachers to draw on these practices in literacy teaching. Moreover they touched on "a Ministry of Education position paper on assessment", which requires assessment through "continual conversations and observations as well as scrutiny of students class work" (p. 33). Dickie and Shuker pointed out that this approach enables teachers to use students' interests while 
collecting assessment data. Finally, the authors demonstrated the importance of incorporating students' expertise of popular culture into literacy learning by capitalizing on several scholars (Marsh and Millard, Luke, and Dyson) views on children's popular culture and its relation to literacy teaching. We felt the necessity to mention the background of the study before starting examining the paper, as knowing what the authors valued enables us to picture how they decided to implement the methods in their research:

The training and personal values of the researcher cannot be ignored. They form a component of the context of social research methods in that they may influence the research area, the research questions, and the methods employed to investigate these. Our experiences and our interests frequently have some influence on the issues we research. As academic social researchers, the issues that interest us have to connect to the wider disciplines of the social sciences (Bryman, 2012, p. 7).

Looking at the above extract, we would contend that by focusing on the background of the study the authors aimed to show us how their values are influenced (Greenbank, 2003) by the values of other scholars. In other words, by providing us with information about the background of their research, they drew attention to their underlying values which then influenced the research process (McLaughlin \& Ayubayeva, 2015). So we can come to the conclusion that, by informing us about the "pre-existing theoretical positions" (Lather, 1986) on "incorporating children's knowledge of popular culture into the school literacy curriculum" (Dickie \& Shuker, 2004, p. 32) the authors actually gave a very clear message as to how these "pre-existing theoretical positions" were used and altered by the research they conducted (Greenbank, 2003). We would argue, therefore, that from the very beginning the researchers' values have an effect on the research process and there is no doubt that these values shape and embody the flow of their research.

Now we want to focus on the methods implemented in Dickie and Shuker's study. As indicated before, in their research the authors aimed to find an answer to what the teachers in New Zealand think about including children's knowledge of popular culture into the literacy curriculum. Thus, in order to arrive at the answer they collected the data from the teachers who were teaching children aged 5 to 8 . The data was gathered in two stages. In the first stage, the teachers teaching the children in years 1 to 3 in 154 primary schools in New Zealand were sent a comprehensive postal survey. Besides responding a range of Likert-scale statements, the teachers also responded "open-ended questions concerning their attitudes, beliefs and experiences regarding children's use of popular culture and the extent to which they incorporated this expertise in their classroom programmes" (p. 34). In the second phase researchers aimed to examine "teachers' and children's use of popular culture in their literacy curriculum" (p. 34) in detail. In order to do this they adopted case studies in three different primary schools in which children's popular culture is valued and used. The researchers also collected data by giving "individual semi-structured interviews" and through observing them in the classes.

It is very obvious that the methods they implemented to gather data in their research process belong to different research paradigms. In the first phase of their study they favoured a quantitative approach by sending comprehensible postal surveys to many teachers in New Zealand. With the survey the teachers were also asked to respond to "open-ended questions concerning their attitudes, beliefs and experiences regarding children's use of popular culture and the extent to which they incorporated this expertise in their classroom programmes" (p. 34). On the other hand, in the second phase of their study they preferred to use a qualitative approach by implementing exploratory case studies. In brief, in their study Dickie and Shuker adopted mixed methods by combining quantitative and qualitative research methods.

Even though in the first phase of the data collection process the researchers used quantitative approach, we would argue that in their study Dickie and Shuker gathered data from an interpretivist perspective because in their paper their main focus is on the teachers' viewpoint on integrating children's experiences of popular culture into the literacy curriculum. As is already known, an interpretive approach provides a deep insight into "the complex world of lived experience from the point of view of those who live it" (Schwandt, 1994, p. 118). When asking open-ended questions to the teachers in their survey, the researchers were expecting the teachers to give their individual, subjective answers on the use of children's popular culture in literacy classes. Thus, different responses from the individuals' different attitudes, concerns and beliefs lead to "multiple realities" (Pring, 2006, p. 42) because every given answer to the open-ended questions was interpreted differently by each researcher due to their individual, and personal differences. On this basis, we would contend that researchers automatically interpreted and constructed the reality by using their own values. Use of open-ended questions in the survey allowed the researchers to bring "such subjectivity to the fore, baked with quality arguments rather than statistical exactness" (Garcia \& Quek, 1997, p. 459). Therefore, this proves that using quantitative approach does not make a research "depersonalised and value-free" (Greenbank, 2003, p. 793). At this point, we also would like to point out that even 
in the preparation process, the survey is influenced by the authors' "competency values" (Greenbank, 2003) because as defined by Rokeach (1973), competency values are the beliefs about finding the best and effective way to do something. Even before data is analysed, interpreted and presented the researcher's method of sampling, experimental design or questionnaires are likely to reflect their values. Thus, in order to receive effective answers on the issue, the authors in their study unavoidably revealed their values in the survey and interview questions.

In the second phase of their study the authors aimed to "explore in depth teachers' and children's use of popular culture in their literacy curriculum" (p. 34) by using case studies. In the same vein, when adopting case studies, the researchers favoured the interpretivist approach and their methods are value-laden because their subjected presence existed and therefore had an effect on the findings. The authors focused on how and why questions to comprehend the teachers' assumptions on the use of children's popular culture into literacy classes. In order to do this they explored the matter in its natural environment. Whilst implementing case studies they "blended numerical and qualitative data" (Cohen et al., 2011, p. 289) and therefore adopted a mixed method and gave strength to the research findings. "Mixed methods are necessary to uncover information and perspective, increase corroboration of the data and render less biased and more accurate conclusions" (Reams \& Twale, 2008, p. 133). While building the case studies, the researchers collected the data from semi-structured interviews, observations and from their detailed survey responses. It could be said, therefore, that their study was an in-depth, reflexive practice, in which they had the freedom "to handle and present the data better" (Berger, 2015, p. 221). Thus through reflexivity the researchers gained a better understanding of the teachers' views on capitalizing on children's expertise in popular culture in their literacy classes. This in-depth and reflexive work required subjectivity because in the data collection process the researchers were participants and they gathered data through interpreting and evaluating observations, interviews and survey responses. When the data is interpreted, researchers' values acted as mechanisms and produced effects (Longhofer \& Floersch, 2014). So, whilst the authors were interpreting and analysing the four teachers' responses to semi-structured interview and survey questions, they were revealing their "voice" (Greenbank, 2003) in which their values about the place of popular culture in the literacy curriculum is embedded.

On this account we would contend that Dickie and Shuker's research cannot be value-neutral as the research preparation and data collection process were influenced by their values.

\section{Discussion}

In this paper we tried to highlight the role and effects of values in research process through accepting the subjectivity of research. All the way through our arguments and judgements, we favoured the stance that research methodologies cannot be value-neutral. While favouring and supporting this stance, we actually reflected our values in this piece of work. The way we pursue to argue the existence of values in the research process is our own subjective way. Consequently, we would contend that this paper itself is very value-laden and reflexive as we used our own interests, beliefs and concerns to generate the ideas in our arguments. In other words, while trying to prove the existence of the values in the methods implemented in the articles, we actually revealed our embedded values concerning the matter.

As discussed in detail, both papers favoured the use of children's popular culture into the literacy curriculum and they conducted their study in order to suggest that inclusion of children's popular culture into the curriculum can contribute to the development of their literary skills and enhance their learning. Actually what the authors value in their papers is what the children value. Their main concern is on children's popular culture, because this is what they believe is very valuable for the children. So our question here is: "Could a study be value-neutral when what is researched is a value itself?" For us the answer is "no" and this is why throughout the paper we tried to demonstrate the existence of values in the papers. Values first appeared in authors' research questions revealed whilst implementing the various methods. Namely action research, participant observations, semi-structured interviews, comprehensive survey questions, case studies and observations. The researchers were active while implementing these methods because they wanted to gain a fruitful understanding of the place of children's popular culture in literacy curriculum. To that end, they scrutinized and examined the children very closely and, therefore, we would contend that this active involvement in the data collection process came with a lot of personal and competency values, as it is impossible to remain objective while interpreting and examining the data. The analysis made in this paper then tells us that in pursuance of the existence of values, our embedded values emerged and we became aware of the fact that valuing what the children value does really motivate and encourage them to reveal their hidden skills. 


\section{References}

Antonio, D. A. (2009). Interpretive research aiming at theory building: Adopting and adapting the case study design. The Qualitative Report, 14(1), 42-60.

Berger, R. (2015). Now I see it, now I don't: Researcher's position and reflexivity in qualitative research. Quantitative Research, 15(2), 219-234. https://doi.org/10.1177/1468794112468475

Braidotti, R. (2013). The Posthuman. Cambridge, UK: Polity Press.

Bryman, A. (2012). Social research methods (4th ed.). New York, Oxford University Press.

Cohen, L., Manion, L., \& Morrison, K. (2011). Research methods in education (7th ed.). New York, Routledge.

Dickie, J., \& Shuker, M. J. (2014). Ben 10, superheroes and princesses: Primary teachers' views of popular culture and school literacy. Literacy, 48(1), 32-38. https://doi.org/10.1111/lit.12023

Elliott-Johns, S., Booth, D., Rowsell, J., Puig, E., \& Paterson, J. (2012). Using student voices to guide instruction. Voices from the Middle, 19(3), 25-31.

Greenbank, P. (2003). The role of values in educational research: The case for reflexivity. British Educational Research Journal, 29(6), 791-801. https://doi.org/10.1080/0141192032000137303

Guba, E. G., \& Lincoln, V. S. (1989). Fourth generation evaluation. London, Sage.

Kemmis, S., \& McTaggart, R. (1988). The action research planner. Geelong, Victoria, Deakin University Press.

Lather, P. (1986). Research as praxis. Harvard Educational Review, 56(3), 257-277. https://doi.org/10.17763/haer.56.3.bj2h231877069482

Longhofer, J., \& Floersch, J. (2014). Values in a science of social work: Values-informed research and research-informed values. Research on Social Work Practice, 24(5), 527-534. https://doi.org/10.1177/1049731513511119

Machado, M. J. (2014). Early childhood experiences in language Arts: Early literacy. Boston, Cengage Learning.

Marsh, J. (2000). "But I want to fly too!" Girls and superhero play in the infant classroom. Gender and Education, 12(2), 209-220. https://doi.org/10.1080/09540250050010018

McLaughlin, C., \& Ayubayeva, N. (2015). "It is the research of self-experience": Feeling the value in action research. Educational Action Research, 23(1), 51-67. https://doi.org/10.1080/09650792.2014.994018

Pahl, K. (2012). Every object tells a story. Home Cultures, 9(3), 303-327. https://doi.org/10.2752/175174212X13414983522152

Pahl, K., \& Rowsell, J. (2011). Artifactual Critical Literacy: A New Perspective for Literacy Education. Berkeley Review of Education, 2(2), 129-151.

Parry, B. (2014). Popular culture, participation and progression in the literacy classroom. Literacy, 48(1), 14-22. https://doi.org/10.1111/lit.12027

Pring, R. (2005). Philosophy of Education: Aims, theory, common sense and research. London, England: Continuum.

Pring, R. (2006). Philosophy of educational research. London: Continuum.

Reams, P., \& Twale, D. (2008). The promise of mixed methods: Discovering conflicting realties in the data. International Journal of Research and Method in Education, 31(2), 133-142. https://doi.org/10.1080/17437270802124509

Rokeach, M. (1973). The nature of human values. New York, The Free Press.

Saccardi, M. (2014). Creativity and children's literature: New ways to encourage divergent thinking. California, Libraries Unlimited.

Scanlan, M. (2010). Opening the box: Literacy, artefacts and identity. Literacy, 44(1), 28-36. https://doi.org/10.1111/j.1741-4369.2010.00544.x

Schwandt, T. A. (1994). Constructivist, interpretivist approaches to human inquiry. In N. K. Denzin, \& Y. S. Lincoln (Eds.), Handbook of Qualitative Research (pp. 118-138). Thousand Oaks, CA: Sage. 
Teichert, L. (2015). Book Review. Journal of Early Childhood Literacy, 15(1), 141-144. https://doi.org/10.1177/1468798414552429

Webb, A. N., \& Rule, A. C. (2012). Developing second graders' creativity through literacy-science integrated lessons on lifecycles. Early Childhood Education Journal, 40(6), 379-385. https://doi.org/10.1007/s10643-012-0532-y

Wohlwend, K. (2011). Playing Their Way into Literacies: Reading, Writing, and Belonging in the Early Childhood Classroom. New York: Teachers College Press.

Wohlwend, K., \& Peppler, K. (2015). All rigor and no play is no way to improve learning. Phi Delta Kappan, 96(8), 22-26. https://doi.org/10.1177/0031721715583957

Wood, L. (2014). Values-based self-reflective action research for promoting gender equality: Some unexpected lessons. Perspectives in Education, 32(2), 37-53.

\section{Copyrights}

Copyright for this article is retained by the author(s), with first publication rights granted to the journal.

This is an open-access article distributed under the terms and conditions of the Creative Commons Attribution license (http://creativecommons.org/licenses/by/4.0/). 